\title{
Responsible Beverage Service Practices: Comparison between India and Australia
}

\author{
Zacharia Joseph" and Joby Thomas ${ }^{\prime}$
}

\begin{abstract}
Sale and consumption of alcoholic beverages have been rising globally. This is making the alcohol industry worth over $\$ 1344$ billion today. This rise in alcohol consumption has not been without its gray shades in the form of alcohol abuse, alcohol-related crimes, accidents and deaths. This paper studies and compares the Responsible Beverage Service practices between India and Australia to understand its scope and impact. The study draws upon review and analysis of research and data from literature and alcohol policies of the two countries. The study reveals the similarities and differences in the approach towards Responsible Beverage Service between these two countries and suggests methods to strengthen this practice in India.
\end{abstract}

Keywords: Responsible Beverage Service (RBS), Alcohol Abuse, Responsible Service of Alcohol (RSA)

\section{Introduction}

Production and sale of liquor have always been a controversial topic in society. Alcohol has been associated with many societal issues ranging from crimes, accidents, poverty, and ill-health. On the other hand, the immense economic benefits it gives not only to people directly involved in its production and sale but to the

\footnotetext{
* CHRIST (Deemed to be University), Bangalore, India; zacharia.joseph@christuniversity.in

† CHRIST (Deemed to be University), Bangalore, India; joby.thomas@christuniversity.in
} 
Government is hard to ignore. The excise revenue estimated in Delhi for the year 2018-19 is Rs 4700 Crore. With Rs 29,672 Crore in the previous year, Tamil Nadu is the top earner from the sale of alcohol among Indian states (India Today, 2016).

With an estimated worth of $\$ 35$ billion, the alcohol market in Indian is the third largest in the world. The legal drinking age ranges between 18 to 25 years depending on individual state law, and with $53 \%$ of the population above 25 years, India provides as a huge market for alcoholic beverages (India Demographic Profile, 2018).

While service of alcohol brings in good profits, hotels and other licensed establishments face the task of balancing profitability with responsibility. While the Excise and the Police departments are responsible for checking and controlling alcohol sales and related issues, the licensed establishments are also required to ensure that alcohol is served and consumed in a safe and socially acceptable manner.

The practice of selling and serving alcohol responsibly is a legal requirement in most countries across the world. But, the strength and scope of these practices vary from country to country and even from state to state. In India, alcohol rules and policies vary from one state to the other.

Though there are rules and laws regarding the sale and service of alcohol throughout the country, its impact has been highly questionable. With sellers as well as consumers breaking the law or finding loopholes in the system, the Government has been forced to completely ban alcohol in a few states. States like Gujarat have decided to go dry by declaring prohibition (The Gujarat Prohibition (Amendment) Act, 2017). But a little research into the history of prohibition will tell us that it has never been effective. While Gujarat is considered a 'dry state', alcohol is available and sold in the black market. Gujarat has in fact, one of the most efficient alcohol distribution networks in the country (India Today, 2016). This black market has deprived the state of the potential revenue it could have made otherwise.

Research has proven that Responsible Beverage service backed by strong alcohol laws and regulations can to a great extent control 
alcohol abuse and intoxication. This paper studies the existing research in Responsible Beverage Service to understand how this practice can create a responsible drinking culture in the country. Further, the best RBS practices in Australia are studied and analysed to understand how RBS is used and implemented in a developed country to create a safe and healthy drinking environment.

\section{Objectives}

1. To examine RBS rules and strategies

2. To suggest best practices in RBS in order to create a responsible drinking culture in the country

\section{Responsible Beverage Service Definition and Strategies}

Initially called Server Intervention, Responsible Beverage Service targets server behaviour. Rossow and Baklien (2010) stated that "Responsible Beverage Service (RBS) is a licensed premises intervention aiming at reducing alcohol-related harms focusing on reducing the availability of alcohol to minors and prevent the service of alcoholic beverages to obviously intoxicated persons". Saltz (1985) mentioned that RBS includes a broad set of strategies to create a safer drinking environment that first, reduces the risk of intoxication and second, reduces the risk that such a person will harm others or even themselves.

Mosher (1983) has divided RBS into three components:-

- Training-This includes the educational programmes directed at employees

- Legal-This includes regulations, laws and dram shop liability

- Environment-this includes establishment layout and design including transport facility

Salt (1985) also mentions that policies should not only be limited to not serving minors or intoxicated customers but also should look into the availability of food and non-alcoholic beverages, acceptable standards of customer behaviour, staffing requirements, transport 
arrangement for intoxicated customers, and management support to servers in implementing RBS.

\section{Research to Date}

O'Donnell (1985) found that about half of the drivers under the influence of alcohol had been drinking in a licensed establishment, and drivers who consumed their last drink in a bar had higher blood alcohol levels. Early research into RBS, like the Navy server Study (Salt, 1987) and Russ and Geller (1987) tried to establish an association between RBS and alcohol abuse. These early studies tried to estimate the impact of RBS on the consumption of alcohol by customers. While early research was able to associate RBS with reduced intoxication, the extent to which RBS impacted alcohol abuse could not be confirmed. A similar study by Rossow and Baklien (2010) in Norway found that the RBS programme in Norway failed to reach its objectives. While RBS could not reach its objectives in Norway, in neighbouring Sweden, the STAD project which translates into Stockholm prevents alcohol and drug problems was found to be highly effective. The failure of RBS in Norway was attributed to a lack of depth in both programme content and policy. The researchers found that state and establishment policies, support of management and programme content and ways of implementation are crucial for any RBS programme to succeed. The key reason for the success of the STAD projects was its interdisciplinary and cross-sector collaboration between key operators who worked together to influence the availability and demand for alcohol. Sweden's equivalent to the RBS is called Ansvars full alkohol servering or AAS. Another reason for the RBS failing in Norway according to Rossow and Baklien was that servers who underwent the RBS programme were not trained on how to evaluate whether customers were underage, already intoxicated or equipped enough to deal with situations where denial of alcohol was needed.

Toomey and Wagenaar (1999) suggested that instead of burdening licensed establishment in providing RBS training to its staff, a more practical and economic approach will be server licensing and certification. Herein, servers are required to meet certain requirements and certification before taking up a job involving 
alcohol. Toomey et al (1998) after doing a qualitative assessment of RBS training programme for servers across the USA found that most of the RBS training programmes across the USA targeted the waiting staff while the crucial owners of the establishments were not required to undergo such a training. The researchers emphasised the need for a uniform standard across the country for training staffs on RBS. Gehman et al (1999) discussed that one of the major reasons for the ineffectiveness of any RBS programme was due to the nature and kind of RBS training provided to the servers. The researchers found that these trainings provided only knowledge-based information and not the skills or incentives necessary to change server behaviour.

\section{Alcohol in India}

India is one of the fastest growing and the third largest market for alcohol in the world. According to the Business Wire (2017) the alcoholic beverage market in India is growing at a CAGR of around $7.72 \%$ over a 10 year period and will reach a value of INR 5.3 trillion by the fiscal year 2026 .

As per the 2014 World Health Organisation's report on alcohol and health, $30 \%$ of Indians regularly consume alcohol and per capita consumption of alcohol annually stood at 4.3 litres.

India's association with alcohol goes way back into history. Alcoholic beverages and its effects are mentioned in ancient historic texts and writings. Ayurveda mentions its use as well as the consequences of its misuse.

The subject of alcohol is included in the state list under the seventh schedule of the Constitution of India. This means that rules regarding the sale and consumption of alcohol are a state issue and each state and union territory has adopted a different approach towards its alcohol policy.

Based on the distribution channel of alcohol in the country, Indian states could be classified into the following three market types:-

- Government-controlled market

- Open market 
- Auction market

In a government controlled market as seen in Kerala and Tamil $\mathrm{Nadu}$, state-run corporations control the entire distribution network. Liquor is bought directly by the state corporations from the producers and are wholesaled and retailed from government liquor shops. The Karnataka government follows a hybrid model where the wholesale distribution is controlled by the state.

In an open market as seen in Maharashtra and Goa, the government issues licenses to distributors and retailers. Here the manufacturers are free to choose their distributor who in turn sells the stock to the retailers.

In the auction system, the state is divided into several geographical regions and the rights of each region are auctioned by the state to the highest bidder. This type of system is found in states such as Haryana and Punjab.

Another major difference that is found across the Indian states is the different legal minimum age for the consumption of alcoholic beverage by a person. In some states, it can be as young as 18 years and goes up to a maximum of 25 years.

Given below are the list of Indian states and Union Territories and the legal age for consuming alcohol-

\begin{tabular}{llr}
\hline \multicolumn{1}{c}{ Legal Drinking Age } & \multicolumn{2}{c}{ States } \\
\hline 18 Years & Andaman Nicobar islands, \\
& Himachal Pradesh, Kerala, \\
& Mizoram, Pondicherry, Rajasthan, \\
& Sikkim years & \\
& Jammu and Kashmir, Andhra \\
& Pradesh, Arunachal Pradesh, \\
& Assam, Chhattisgarh, Dadra and \\
& Nagar Haveli, Daman and Diu, Goa, \\
& Jharkhand, Karnataka, Madhya \\
& Pradesh, Orissa, Tamil Nadu, \\
& Telangana, Tripura, Uttar Pradesh, \\
& West Bengal, Uttarakhand \\
& Delhi, Chandigarh, Meghalaya, \\
& Punjab, Haryana \\
& Nagaland, Manipur, Lakshadeep, \\
& Bihar, Gujarat \\
\hline
\end{tabular}




\section{Responsible Beverage Service in India}

Though there are strict laws and rules regarding the service of alcohol on the licensed establishment in many countries, in India it has mostly been practised on a more ethical basis and also in times when the situation has gone out of control, wherein the patrons had turned unruly and difficult to control.

\subsection{Restriction with respect to the location of the shops}

No alcoholic beverage can be sold near any religious and educational institution, hospital, state, or central government office. A minimum distance of 100 meters needs to be maintained between a licensed establishment and any such place. No sale of alcohol is allowed within 500 meters of any state or national highway.

The following rules are issued by the Excise department regarding the sale and consumption of alcohol in the state (Vohra, 2016).

Sale of alcohol is not allowed in most states on
a. 2nd October
b. Republic Day
c. Independence Day
d. During Government elections and counting
e. Prevention of public peace

Sale of alcohol is prohibited to

a. People with a mental disorder

b. A person already intoxicated

c. A person suspected to take part in any unlawful activity, riot or the disruption of public peace

d. Excise officials, police officers, railway servants and motor bus chauffeur, on duty or in uniform

e. A person under the minimum age limit set by the state

While few star hotels and upscale bars and restaurants are able to implement some policies regarding RBS to some degree of success, it is ignored in the majority of the liquor shops, local bars, and restaurants catering to the general population. 


\section{Drinking Culture in India and Australia}

Compared to Australia's wet culture where alcohol is integrated into the society, India by tradition has been known to be dry or a culture that practises abstaining. In comparison, the per capita consumption of alcohol between the two countries shows that while alcohol consumption in Australia has come down from 10.04 litres in 2012 to 9.39 litres in 2017, an all-time low in the last 50 years, in India it has doubled since 2005 to 2017. Data for 2016 shows the per capita consumption at 5.7 litres (Foundation for Alchol Research and Education, 2017). Though per capita consumption in India is less, it is growing with more youngsters coming of age. While $80 \%$ of the population consumes alcohol in Australia, in India it is only $30 \%$. While the alarming drinking culture in Australia is that of 'Preloading', a practice of consuming alcohol in the house or outside before going to a bar or a restaurant to drink more, the practice of heavy episodic drinking or binge drinking is a major concern back home. Therefore while an average Indian consumes alcohol less regularly than his Australian counterpart, his occasional drinking episodes more likely result in alcohol abuse and intoxication.

Both India and Australia have considered the "Global Strategy to Reduce the Harmful use of alcohol" issued by the World Health Organisation (WHO, 2010). True to the WHOs statement that developed or higher income countries are more likely to introduce these policies; Australia has taken key steps in controlling its alcohol issues coming up with a clear and documented National Alcohol Strategy for 2018-2026. Though India has considered the guidelines laid down by $\mathrm{WHO}$, it is still in the formulation stage and far from being implemented.

\section{Responsible Beverage Service Policies and Practices in India and Australia}

Responsible Beverage Service is considered as a soft approach to the Indian scenario. With no mention of RBS in any Government or Excise department in India, Indian policymakers have in fact completely ignored RBS. Though RBS measures like not serving alcohol to a minor or to an intoxicated person are written down, its process and implementation are not defined. Alcohol intoxication is 
considered a matter of personal responsibility with no liability to the licensed establishment.

Alcohol is identified as the second leading preventable cause of death after tobacco in Australia. Rules and practices regarding Responsible Beverage Service (RBS) or Responsible Service of Alcohol (RSA) across the world all have a common objective of reducing, controlling, and terminating the harm caused by alcohol abuse and intoxication. Though the objectives are common, the approach to RBS could vary from one country to another. Most of the developed countries like the USA, the UK, and Australia have well-established laws, rules, and regulations concerning RBS.

It might not be advisable to plainly copy and implement RBS strategies from one country into another but it will definitely benefit to understand how a systematic and holistic approach could be taken in implementing RBS. The RBS policy and strategies in Australia could be used as a framework or model in developing the same for Indian states. RBS policy and rules in Australia are both strict and clear. Making RBS training and certification compulsory for any server or person involved in sale and service of alcohol ensures their ability to identify signs of intoxication in patrons.

\section{Alcohol Policy}

- Strict Government rules and regulations regarding licensed premises and service personnel in controlling alcohol intoxication

- The primary objective of the Australian liquor act is harm minimisation

- Three Strikes Scheme - A warning system where an establishment is given a warning and few benefits are taken away or a penalty imposed for each time a rule is broken; With each breach of rule the action taken being more severe

- RBS training compulsory for all individuals dealing with sale and service of alcoholic beverage; also includes the security staff 
- Signage displayed in licensed premises regarding government alcohol policies

- Breath analysis machines placed in bars

\section{RBS Strategies Used}

- Offer free water, food and non-alcoholic drinks at regular intervals

- Promote low alcohol, non-alcoholic beverages and food

- Stopping the service of stronger beverages late at night

- Fixed number of drinks that can be purchased at one time

- Instead of topping up the drinks, waiting for patrons to reorder

- Post RBS and responsible drinking messages in the establishment

- Have RBS marshals to monitor service and consumption in patrons

- Conducting security patrols in the establishment

- Encourage patrons at risk of intoxication to order food and soft drinks and offer discounts if needed

\section{Conclusion and Recommendation}

While the Excise Department in India has clearly stated the rules and regulations regarding sale and service of alcohol (unlike Australia), there is no evidence of a clear strategy from any state in India on how to implement or practice RBS. The Indian approach is more reactive than proactive. While there is routine checking by the law enforcement department for drunk driving especially on weekends and holidays, the restaurant or bar where the person got intoxicated is never questioned or is never held answerable. While more alcohol is consumed in Australia than India, it's the drinking culture in India which is worrying. A high portion of drinkers in India drinks heavily on single occasions. Referred to as binge drinking, it is this type of consumption which is the major cause of 
alcohol crimes and accidents in India. RBS programme's effectiveness in Australia could be attributed to strict government policies and liabilities in not practising RBS in premises. Therefore, for RBS to be practised and be effective in India, it should be supported by strong policies, management support, and liability in failing to follow RBS.

\section{References}

Foundation for Alcohol Research and Education. (2017). Australia, an intoxicated society-40 year on from the Baume report. FARE:Canberra.

Gehan, J. P., Toomey, T. L., Rhonda, J., Rothstein, C., \& Wagenaar, A.C. (1999). Alcohol outlet workers and managers: focus groups on responsible service practices. Journal of Alcohol and Drug Education $44(2), 60-71$.

Index Mundi. (n.d.). Demographics. Retrieved October 30, 2018, from https://www.indexmundi.com/india/demographics_profile.html

India Today. (2016, October 08). See if your state is among top ten booze revenue earners. Retrieved from https:// www.indiatoday.in/ india/ story/booze-revenue-alcohol-

economy-prohibition-tamil-nadu-bihar-supreme-court-345588-2016-10-08

LPAD. (n.d.). The Gujarat Prohibition Amendment Act. Retrieved from https://lpd.gujarat.gov.in/gujacts/the-gujarat-prohibitionamendment-act-2017

Mosher, J. F., Toomey, T. L., Good, C., Harwood, E., \& Wagenaar, A. C. (2002). State Laws Mandating or Promoting Training Programs for Alcohol Servers and Establishment Managers: An Assessment of Statutory and Administrative Procedures. Journal of Public Health Policy, 23(1), 90-113. doi:10.2307/3343120

Odonnell, M. A. (1985). Research on drinking locations of alcoholimpaired drivers: implications for prevention policies. Journal of Public Health Policy, 6(4), 510-525. doi:10.2307/3342050

Rossow, I., \& Baklien, B. (2010). Effectiveness of responsible beverage service: The Norwegian experiences. Contemporary Drug Problems, 37(1), 91-107. doi:10.1177/009145091003700105

Russ, N. W., \& Geller, S. (1987). Training bar personnel to prevent drunken driving: A field evaluation. American Journal of Public Health, 77(8), 952-954.

Saltz. R.F. (1998) Server intervention and responsible beverage service programs, pp. 168-179. Prevention Research Center Berkeley, California. 
Toomey, T. L., \& Wagenaar, A. C. (1999). Policy options for prevention: the case of alcohol. Journal of Public Health Policy, 20(2), 192-213.

Vohra, B. (2016, July 18). Alcohol laws in India. Retrieved from https:// www.lawfarm.in/blogs/alcohol-laws-in-india

Williams, A., Moore, S. C., Shovelton, C., Moore, L., \& Murphy, S. (2016). Process evaluation of an environmental health risk audit and action plan intervention to reduce alcohol related violence in licensed premises. BMC Public Health, 16(1). doi:10.1186/s12889-016-3123-9

WHO. (2018). Global Status Report on Alcohol and Health. Retrieved October 30, 2018, from http://www.who.int/substance_abuse/ publications/global_alcohol_report/en/ 